\title{
Early Neuroendoscope-assisted Evacuation of Spontaneous Intracranial Hematomas. Preliminary Report
}

\author{
Tony Avramov MD, PhD; Yavor Enchev MD, PhD, Bogomil Iliev MD, \\ Dejan Handzhiev MD, Tony Kondev MD \\ Department of Neurosurgery, St. Marina University Hospital, \\ Medical University, Varna, BG
}

\begin{abstract}
Purpose: The surgical techniques, effectiveness and indications of microsurgical neuroendoscopic assisted evacuation of spontaneous intracranial hematomas (SICH) is still uncertain. This minimal invasive technique remains investigational and controversal with regard to patient selection, timing of operation and method of the management. The purpose of this study was to investigate the early postoperative results in patients with SICH underwent endoscopic evacuation and to give evaluation and eventual prognosis of the clinical outcomes after this procedure.

Material and Methods: A retrospective analysis of 56 patients SICH treated in the Neurosurgical clinic with endoscopic assisted evacuation was performed. Hematoma volume and its localization (subcortical - 11 patients, in basal ganglia - $12-7$ of them with propagation to ventricular system, 6 infratentorial and 27 subdural), comorbidity, clinical features and timing of surgical procedures was made. The GCS rate by admission and GOS by discharging of patients was analyzed, also the postoperative complications and causes of death.

Results: 52 patients $(92,9 \%)$ were operated within the first 24 hours of the onset. Patients operated between the 12 and 24 hours had better outcome in comparison to these operated after the 24 hours period. The authors analyzed their experience with endoscopic technique, effectiveness of the method, results and complications. Mortality rate in our series was 23, $2 \%$ (13 patients). The causes of surgical complications and causes of death were analyzed.

Conclusion: The endoscopic assisted evacuation of SICH is a short, safe and very effective method when the surgical procerure is provided within the first 12-24 hours. Our results showed that early and complete evacuation of hematoma volume may promote to recovery of the general condition of the patient and improved outcomes.
\end{abstract}

Key words: spontaneous intracranial hematomas - minimally invasive technique - neuroendoscope-assisted evacuation - timing of operation - complications

\section{Introduction}

Spontaneous intracranial hemorrhage $(\mathrm{SICH})$ is the common used term in the literature for intracerebral hemorrhage. SICH are accounted for $10 \%$ to $15 \%$ of all strokes and show the highest risk of disability and mortality $-35 \%$ to $52 \%$ of patients die within a month and half of them within the first 48 hours. Another half of the survivors are severely disabled $(3,7,9-17,19-21$, 29-31, 34-37, 41, 42). According to Sung et al (2012) the incidence rate of non-traumatic causes of SICH is $3 \%$ to $5 \%$ with the most frequent predisposing factors like hypertensive arteriosclerosis, cerebral amyloid angiopathy, other vascular abnormalities, some hematological disorders (acquired coagulopathy) and results of anticoagulant therapy. Studies of ICH treatment yet give no consistency of selection criteria and therapeutic models which patients group are indicated to the surgical treatment and which to conservative one, because of the variety of selection criteria for patient inclusion. Numerous surgical trials published controversial results until The International Surgical Trial in Intracerebral Hemorrhage (ISTICH) in 2003 aimed at this direction determined the criteria for surgical treatment within the first 24 hours, based on neurological condition, neuroimaging findings, size of the hematoma, age, some clinical and laboratory parameters and which can also predict the outcome of surgery or determine the patients to best conservative therapy $(2,3,6,7,11-14$, $17,19,22,29,30,33,35,36)$. Open craniotomy was performed in $77 \%$ of patients for removal of SICH and in the remaining cases - minimally invasive operative technique like frameless stereotaxy and endoscopy (4- 
$6,8-10,16,23,35,37,39-42)$. When comparison was made between initial conservative treatment and early operative removal of $\mathrm{SICH}$, the trial did not reveal-any benefits $(6,7,11,14,15-17,19-21$, $26,31,33,38)$. In the last years new clinical trial devoted to minimally invasive operative methods recommended combination of minimally invasive surgery techniques like stereotactic or endoscopic aspiration and cloth thrombolysis for the reduction of hematoma volume $(11,35)$. But the indications and effectiveness of the new operative techniques for early neuroendoscope-assisted evacuation according to the AHA/ASA guidelines for the management of SICH is still uncertain $(1,2,5-7$, $11,14-17,19-22,30,31,33)$. This minimal invasive technique according to many authors remains investigational and controversal with regard to patient selection, timing of operation and method of the surgical management $(1,3,5,8,9-11,13,15$, $17,20,23-28,30,32,35,36,39-42)$.

\section{Material and Methods}

The purpose of this study was to investigate the early postoperative results in patients with $\mathrm{SICH}$ underwent endoscopic evacuation and to give evaluation and eventual prognosis of the clinical outcomes after this procedure.

In this study we include 56 consecutive admitted patients in our Neurosurgical clinic from January to December 2012 with ICH of spontaneous origin such as - hypertensive causes, iatrogenic coagulopathies after anti-aggregant or anticoagulation therapy and excluded patients with post-traumatic intracranial hematomas, hematomas after arteriovenous malformation bleeding or tumor hemorrhage. There are 33 men and 23 women divided into 5 age groups: from 40 to 50 years -4 patients, $51-60-10$ patients, 61-70 - 14 patients, 71-80 - 24 patients and over 81 years -4 patients. The co-morbidity consists of 43 patients who have hypertensive disease severe degree, 6 patients with disbalanced diabetes, 5 with chronic kidney insufficiency and 39 patients treated with anti-aggregant or anticoagulation drugs. CT by admission confirmed 20 cases with acute subdural hematoma (ASH), 7 with chronic subdural hematoma (HSH), 11 with subcortical (lobar) hemorrhage, 12 with basal ganglia hematoma 7 of them with intraventricular extension and 6 - with cerebellar hematoma. The volume of intracerebral hematoma in patients estimated for endoscopical treatment was over $30 \mathrm{ml}$. Unlike the other authors we include patients with Glasgow Coma Scale (GCS) score under 8 points. According to GCS 26 patients were estimated on admission day between 15 and 13 points, 20 - between 9 and 12 and 10 patients under 8 points. With severe hemiparesis were 43 patients and the other 13 were without neurological deficits.

For all subdural hematomas we performed vertical skin incision over the crossing point of superior temporal line and coronary suture followed by temporal muscle splitting and craniotomy showed single burr hole $25 \mathrm{~mm}$ in diameter. Dural opening consists of cruciate dissecting. Using balanced suction - irrigation method through transparent plastic tube inserted into the subdural space under endoscopic control we slowly evacuate the hematoma. For basal ganglia we used the most practically transtemporal approach with the same technical equipment. Cortical incision was made possibly near to outer hematoma border. Angled 30 to 70 degree endoscope was introduced through the transparent plastic tube along the whole hematoma diameter for better visualization control (Fig. № 7 and № 8). Evacuation began with slowl and mild suction of the clots so that the suction trajectory was planed according to the longest hematoma axis from in to out. In these eloquent areas we have preference for evacuation with leaving of minimal hematoma volume - single clots adherent usual to the medial wall of hematoma cavity such as atraumatic and preventing unexpected intraoperative re-bleeding. We preferred to make hemostasis with prolonged irrigation with saline solution and suction, excepting cases with plentiful bleeding requiring to use bipolar coagulation (Fig. № 9 and № 10). When the hemorrhage is associated with ventricular extension we provide an external ventricular drainage for a few days, but do not open the ventricle. The cerebellar hematoma are reached through suboccipital burr-hole craniectomy by the same method. When the bleeding extents to the fourth ventricle an external ventricular drainage was left for several days as prevention of hydrocephalia. The subcortical (lobar) hematomas were evacuated through transsulcus intergiral approach in relatively non-eloquent area using the shortest distance between the cortical surface and the hematoma as possible, so that the plastic tube was introduced to the longest diameter of hematoma and clots in the hematoma cavity were removed in direction from in to out (Fig. № 5 and № 6). At the 
end of the surgical procedure the blood pressure was elevated to $160-180 \mathrm{~mm} / \mathrm{Hg}$ to proof the hemostasis in the hematoma cavity. Post-operatively all patients were ventilated and received prophilactic antibiotics, antiedema therapy, anticonvulsants and low molecular weight heparins (Clexan) from the day after the surgery. The blood pressure was well controlled and if required on agitated patients sedatives were given. Tracheostomy was done in patients who required prolonged ventilation. All patients repeat mandatory $\mathrm{CT}$ image 24 hours after the surgery.
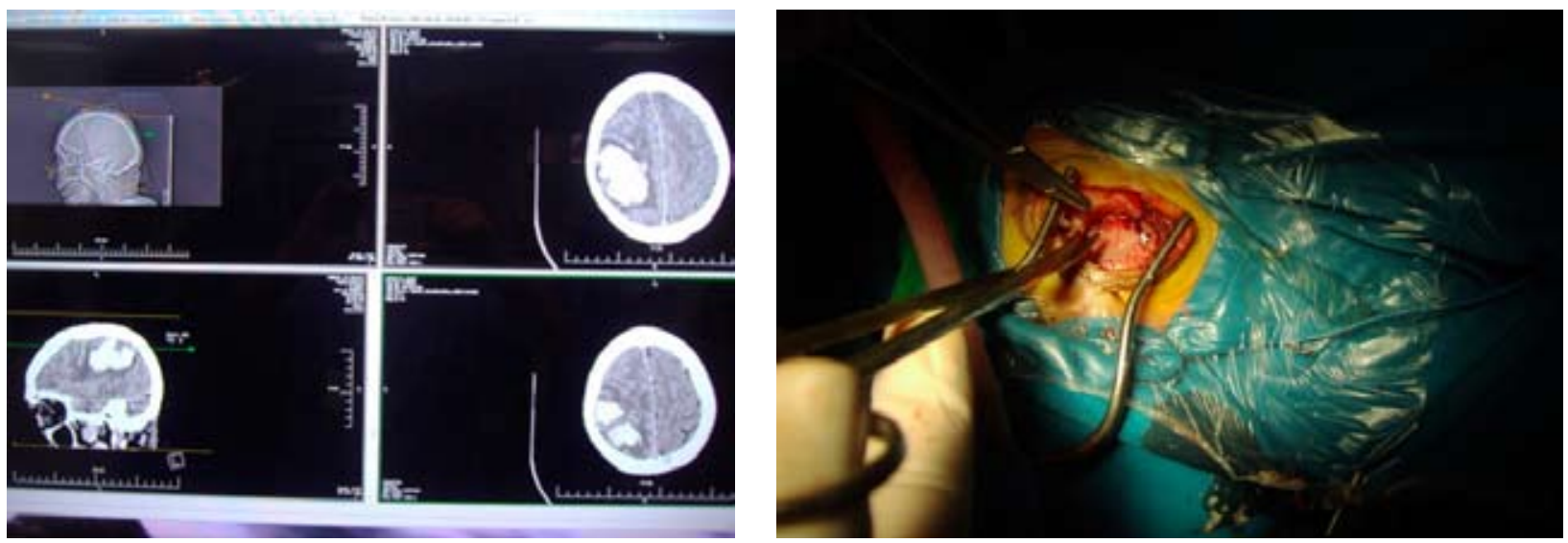

Fig. № 5 and № 6. Intracerebral hematoma in the parietal lobe. Key hole craniotomy is done.
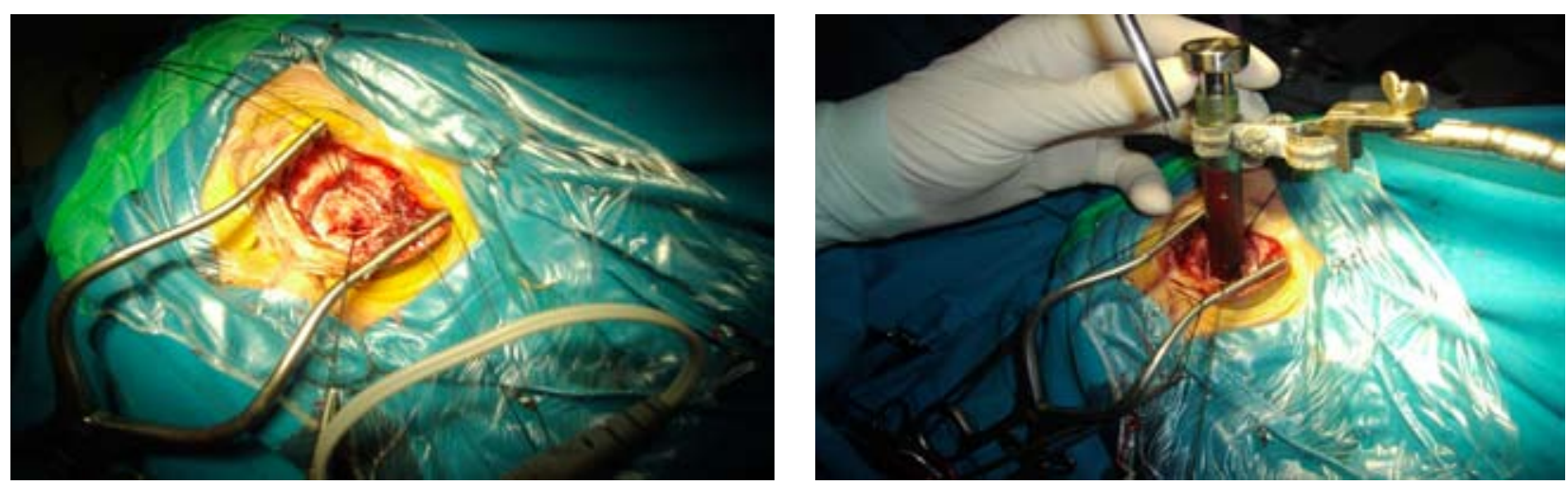

Fig. № 7 and № 8. Dura is opened and the plastic tube is inserted into the hematoma cavity.
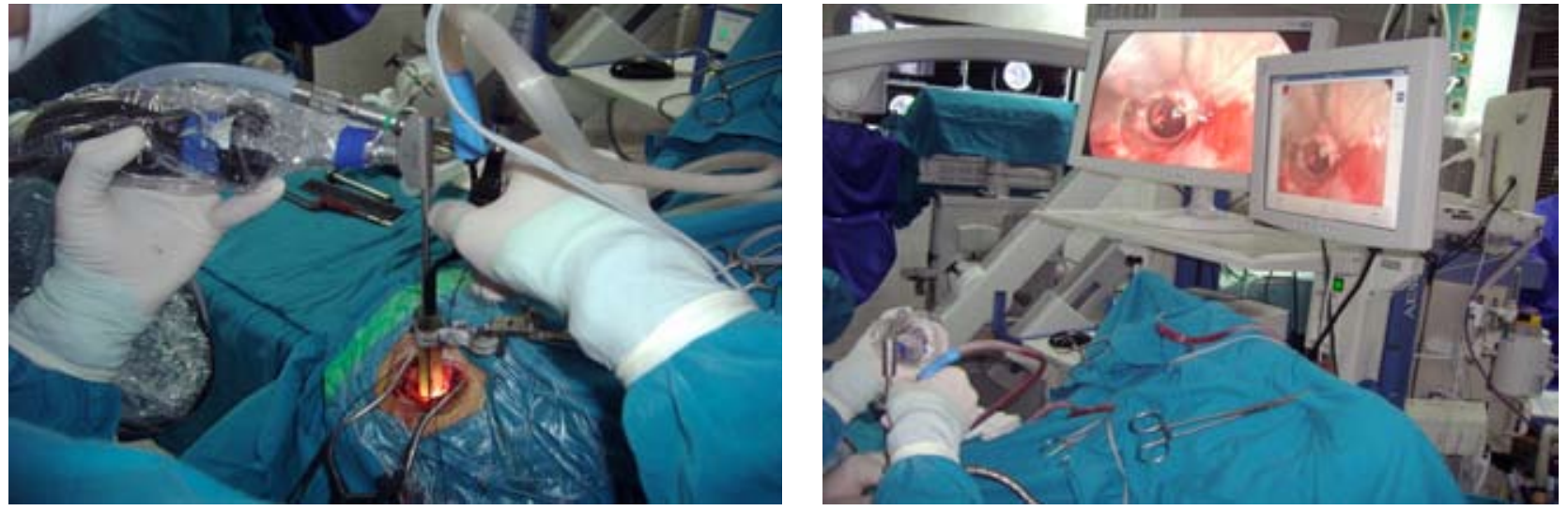

Fig. № 9 and № 10. Endoscopically controlled evacuation of the hematoma volume through the transparent plastic tube (irrigation and bipolar cogulation). 
In the assessment of the early postoperative results we discussed the timing of operative procedure, the frequency of re-bleeding, CT results of the evacuated hematoma volume, the postoperative complications as well as causes of death. We fixed three periods of the performed operative procedure: within 12 hours after the onset were operated 35 patients, between 12 and 24 hours - 17 and from $24^{\text {th }}$ to $48^{\text {th }}-4$ patients. The hematoma volume was estimated according to formula $\mathrm{V}=\mathrm{L} \times \mathrm{W} \times \mathrm{Th}$ divided in two (Kothari). Re-bleeding was find out when the hematoma volume on the postoperative CT image done up to the $24^{\mathrm{h}}$ after the operation was the same or greater than the preoperative volume. The outcome status of all patients after the operative treatment was estimated by Glasgow Outcome Scale (GOS). We try to define a clinical grading scale for ICH which uses criteria that are predictive of outcome - give some prognosis and that can be rapidly and accurately assessed at the time of treatment.

\section{Results}

The operated patients were 56 (33 males and 23 females) distributed into five ages groups. The multitude group was between $7^{\text {th }}$ and $8^{\text {th }}$ decade - 24 patients $(42,9 \%)$ followed by group between $6^{\text {th }}$ and $7^{\text {th }}$ decade -14 patients $(25,0 \%)$, between the $5^{\text {th }}$ and $6^{\text {th }}$ decade -10 patients $(17,9 \%)$ and 4 patients $(7,1 \%)$ identical into the groups $40-50$ age and 81-90 age. Among all 56 patients 43 (76, 8\%) had hypertensive disease severe degree, 6 patients $(10,7 \%)$ were with disbalanced diabetes, $5(9,0 \%)$ with chronic kidney insufficiency and 39 patients $(69,6 \%)$ were treated with anti-aggregant or anticoagulation drugs.

The most common type of ICH was the acute subdural hematoma (ASH) - 20 cases $(35,7 \%), 7$ $(12,6 \%)$ were chronic subdural hematoma (HSH), $11(19,6 \%)$ subcortical (lobar) hemorrhage, 12 $(21,4 \%)$ basal ganglia hematoma, 7 of them with intraventricular extension and $6(10,7 \%)$ - cerebellar hematoma. With severe hemiparesis were 43 patients $(76,8 \%)$ and the other $13(23,2 \%)$ were without neurological deficits. Twenty-six patients $(46,4 \%)$ were estimated on admission day between 15 and 13 point according to GCS, $20(35,7 \%)$ - between 9 and 12 and 10 (17, 9\%) patients under 8 points. (Figure № 1 ).

Thirty-five patients $(62,5 \%)$ underwent surgical treatment within the first 12 hours after the onset,
$17(30,4 \%)$ - between 12 and 24 hours and only $4(7,1 \%)$ patients were treated surgically after 24 hours of the onset. (Fig. № 2)

Good outcome was seen in 9 of all 56 operated patients $(16,0 \%)$ within the first 24 hours of the ictus. With mild disability were 20 patients $(35,8 \%)$, 10 patients $(17,8 \%)$ were severe disabled 3 of them operated after 24 hours, $4(7,2 \%)$ stay in vegetative status and 13 patients $(23,2 \%)$ die. Patients operated between the 12 and 24 hours had better outcome in comparison to these operated after the 24 hours period. Mortality rate in our series was 23, $2 \%$.(Fig. № 2) Irrespective that $62,5 \%$ of the patients were operated within the first 12 hours after the onset and the hematoma volume was practically fully evacuated, unsatisfactory results are due to not only the fact that $75 \%$ of the patients are between 61 and 90 years, but because of great number of comorbidity $-96,4 \%$. The results in this group depended also on GCS at admission, on the location and volume of the hematoma and not least on the treatment with antiaggregants and anticoagulant drugs.

The volume of the hematoma estimated on the CT scan varied from $30 \mathrm{ml}$ to over $95 \mathrm{ml}$.

In all patients during the surgery a significant hematoma reduction was achieved. Nevertheless all patients were examined on repeated CT scan postoperatively after the $24^{\text {th }}$ hour. Subtotal to near total evacuation was seen in 27 patients $(93,1 \%)$ from all 29 with intracerebral hematomas. In the remaining 2 patients the repeated CT scan showed an enlargement of the hematoma volume resulting in re-bleeding after the surgery. The surgical outcome status of all patients after the operative treatment was assessed by Glasgow Outcome Scale (GOS). There were: Category 5 - Good Recovery - 9 patients (16,0\%), 4 - Moderate Disability - 20 patients $(35,8 \%), 3$ - Severe Disability -10 patients $(17,8 \%), 2$ Vegetative State -4 patients (7, $2 \%$ ) and $1-$ Dead -13 patients (23, 2\%). (Figure № 3) As shown on Fig. №3, better results (good recovery) were obtained only within the patient group with $\mathrm{SDH}-9$ patients, irrespectively that the age group was between 58 и 84 years. With moderate disability are reported 13 patients with SDH - 3 with lobar and 2 patients in each group with hematomas in the basal ganglia and intracerebellar. Severely disabled were 10 patients between 68 and 79 years. In vegetative state remain 4 patients - from 65 to 84 years, and another 13 patients died -2 patients with SDH, 4 patients with lobar, 
another 4 in basal ganglia and 3 with intracerebellar hematomas. On Fig. № 4 is shown the distribution between the hematoma volume in mililitres and its location in the brain of the patients with intracerebral hematomas.

\begin{tabular}{|l|c|c|c|c|}
\hline \multirow{2}{*}{ GCS } & \multirow{2}{*}{$\begin{array}{c}\text { SDH } \\
(\mathbf{n}=\mathbf{2 7})\end{array}$} & \multicolumn{3}{|c|}{$\begin{array}{c}\text { INTRACEREBRAL } \\
\text { HAEMATOMA }\end{array}$} \\
\cline { 3 - 5 } & & $\begin{array}{c}\text { Lobar } \\
(\mathbf{n}=\mathbf{1 1})\end{array}$ & $\begin{array}{c}\text { In basal } \\
\text { ganglia } \\
(\mathbf{n}=\mathbf{1 2})\end{array}$ & $\begin{array}{c}\text { Cerebellar } \\
(\mathbf{n}=\mathbf{6})\end{array}$ \\
\hline $15-13(\mathrm{n}=26)$ & 17 & 5 & 3 & 1 \\
\hline $12-9(\mathrm{n}=20)$ & 5 & 6 & 6 & 3 \\
\hline$<8(\mathrm{n}=10)$ & 5 & - & 3 & 2 \\
\hline Total $(\mathrm{n}=56)$ & 27 & 11 & 12 & 6 \\
\hline
\end{tabular}

Fig. № 1. Estimation of the admitted patients with $\mathrm{ICH}$ according to GCS.

\begin{tabular}{|c|c|c|c|c|c|}
\hline \multirow{2}{*}{$\begin{array}{l}\text { Timing of } \\
\text { operation } \\
\text { (hours) }\end{array}$} & \multicolumn{5}{|c|}{ GOS } \\
\hline & $\begin{array}{c}5 \\
(n=9)\end{array}$ & $\begin{array}{c}4 \\
(n=20)\end{array}$ & $\begin{array}{c}3 \\
(n=10)\end{array}$ & $\begin{array}{c}2 \\
(n=4)\end{array}$ & $\begin{array}{c}1 \\
(n=13)\end{array}$ \\
\hline $\begin{array}{l}8-12 \\
(n=35)\end{array}$ & 6 & 12 & 4 & 2 & 11 \\
\hline $\begin{array}{l}12-24 \\
(n=17)\end{array}$ & 3 & 8 & 3 & 1 & 2 \\
\hline $\begin{array}{l}24-72 \\
(n=4)\end{array}$ & - & - & 3 & 1 & - \\
\hline $\begin{array}{l}\text { Total } \\
(\mathrm{n}=56)\end{array}$ & 9 & 20 & 10 & 4 & 13 \\
\hline
\end{tabular}

Fig. № 2. Relationship between the timing of operation and postoperative results according to GOS.

\begin{tabular}{|c|c|c|c|c|}
\hline \multirow[b]{2}{*}{ GOS } & \multirow[b]{2}{*}{$\begin{array}{c}\text { SDH } \\
(n=27)\end{array}$} & \multicolumn{3}{|c|}{$\begin{array}{c}\text { INTRACEREBRAL } \\
\text { HAEMATOMA }\end{array}$} \\
\hline & & $\begin{array}{l}\text { Lobar } \\
(n=11)\end{array}$ & $\begin{array}{c}\text { In basal } \\
\text { ganglia } \\
(n=12)\end{array}$ & $\begin{array}{l}\text { Cerebellar } \\
\qquad(n=6)\end{array}$ \\
\hline $5(n=9)$ & 9 & - & - & - \\
\hline $4(n=20)$ & 13 & 3 & 2 & 2 \\
\hline $3(n=10)$ & 2 & 3 & 4 & 1 \\
\hline $2(n=4)$ & 1 & 1 & 2 & - \\
\hline $1(n=13)$ & 2 & 4 & 4 & 3 \\
\hline Total $(n=56)$ & 27 & 11 & 12 & 6 \\
\hline
\end{tabular}

Fig. № 3. Clinical outcomes of the patients with $\mathrm{ICH}$ according to GOS.

\begin{tabular}{|l|c|c|c|}
\hline \multirow{2}{*}{$\begin{array}{c}\text { Hematoma } \\
\text { volume }(\mathbf{m l})\end{array}$} & \multicolumn{3}{|c|}{ ICH } \\
\cline { 2 - 4 } & $\begin{array}{c}\text { Lobar } \\
(\mathbf{n}=\mathbf{1 1})\end{array}$ & $\begin{array}{c}\text { In basal } \\
\text { ganglia } \\
(\mathbf{n}=\mathbf{1 2})\end{array}$ & $\begin{array}{c}\text { Cerebellar } \\
(\mathbf{n}=\mathbf{6})\end{array}$ \\
\hline $30-50(\mathrm{n}=11)$ & 3 & 6 & 2 \\
\hline $50-70(\mathrm{n}=9)$ & 4 & 2 & 3 \\
\hline $70>(\mathrm{n}=9)$ & 4 & 4 & 1 \\
\hline Total $(\mathrm{n}=29)$ & 11 & 12 & 6 \\
\hline
\end{tabular}

Fig. № 4. Distribution between the hematoma volume and its location.
Good outcome was noted in 3 patients $(27,2 \%)$ of all 11 lobar ICH with a volume between 30 an 50 $\mathrm{ml}$, in 2 patients $(18,9 \%)$ from all 12 with basal ganglia location and in another $2(33,3 \%)$ of all 6 with cerebellar hematomas. (Fig. № 3) From all 29 patients operated with ICH and volume 50 to 70 $\mathrm{ml}$ were 9 patients $(31,0 \%)-4$ of them with lobar (3 of them severely disabled after the operation), 2 with basal ganglia hematoma and 3 with cerebellar hematoma (severe disabled from them one patient). Nine patients $(31,0 \%)$ with volume up to $70 \mathrm{ml}$ were operated -4 with lobar location, 4 in basal ganglia and 1 cerebellar. (Fig. № 4) In vegetative state fall 1 patient 65 years old with SDH, one 79 years old with lobar hematoma and 2 patients (61 and 84 years) with location of the hematoma in the basal ganglia. (Fig. № 3) All 13 patients who didn, $\mathrm{t}$ survive were with severe comorbidity, GCS $<8$ points and operated within the first 12 hours after the onset. Two of them were with SDH (76 and 95 years old), 4 with lobar hematoma (51 to 79y), 4 with location in the basal ganglia with penetration to the ventricular system (46 to 61y) and 3 (67-69y) with cerebellar hematomas. In all 10 patients with severe disability and the 4 remaining in vegetatite state in the postoperative period the most common reason for neurological deterioration was reviewed brain ischemia. In four patients in early postoperative period was determined dural tearing from the operative wound, but mastered after operative revision. The most frequent complications in the postoperative period leading to fatal exit were: respiratory failure due to hypostatic pneumonia - in 3 cases, pulmonary embolism - in 3, brainstem stroke - in 2 and bacterial meningitis provoked from Acinetobacter baumannii in 4 cases and Klebsiella infection in one.

On the grounds of the discussed results in our study we proposed a grading scale for assessment of the advance of eventual complications and unfavourable outcome after the surgical treatment. (Fig. № 11) Depending on available criteria: age, volume and location of the hematoma, GCS at admission, comorbidity and timing of the conducted surgical procedure we would indicate the eventually prognosis for the patient in the postoperative period. The receiving points would give estimation of the eventual outcome from the performed treatment. We suppose that worse prognosis will be at 7 points and up because the maximum number points are 11. 


\begin{tabular}{|l|l|c|}
\hline \multicolumn{2}{|l|}{ Index } & score \\
\hline \multirow{4}{*}{ Age } & $<50$ & 0 \\
\cline { 2 - 3 } & $51-69$ & 1 \\
\cline { 2 - 3 } & $70>$ & 2 \\
\hline \multirow{4}{*}{ Volume $(\mathrm{ml})$} & $30-50$ & 0 \\
\cline { 2 - 3 } & $50-70$ & 1 \\
\cline { 2 - 3 } & $70>$ & 2 \\
\hline \multirow{4}{*}{ Gocation } & Lobar & 0 \\
\cline { 2 - 3 } & Deep ganglia & 1 \\
\cline { 2 - 3 } & Ventricular extension & 2 \\
\hline \multirow{3}{*}{ Timing of OP $(\mathrm{h})$} & $15-13$ & 0 \\
\cline { 2 - 3 } & $13-9$ & 1 \\
\cline { 2 - 3 } & $<8$ & 2 \\
\hline \multirow{3}{*}{ Comorbidity } & $<12$ & 1 \\
\cline { 2 - 3 } & $12-24$ & 2 \\
\cline { 2 - 3 } & $24>$ & 1 \\
\hline
\end{tabular}

Fig. № 11. The presumable prognostic scale for assessment of the patient with $\mathrm{SICH}$ in the postoperative period and defining the prognosis.

\section{Discussion}

Spontaneous intracerebral haemorrhage (SICH) together with subarachnoid haemorrhage (SAH) represent only $9 \%-25 \%$ of all strokes, they have been estimated to cause more than $50 \%$ of the overall stroke mortality and more than half of the survivors are severely disabled $(2,3,12-15,19$, $21,29,33,36)$. In the literature are described 36 selected studies devoted to systematic analysis and review of the incidence, case fatality and functional outcome of intracerebral hemorrhages ranged period 1983 - 2006 included 8145 patients with intracerebral hemorrhage. The ascertained incidence rate was 24, 6 per 100000 person of the population pro year (van Asch et al, 2010). Many authors shared that the level of disability and mortality depends on the GCS score, size and location of the SICH, ventricular extension, patient age and not least - on comorbidity. One of the most commonly used clinical indications for surgery is neurological deterioration, but this is also a predictor of poor outcome. Usually surgery has been undertaken in younger patients with worsening or deterioration of GCS scores and slightly larger hemorrhage $(2,3,13,15,21)$. Endoscope assisted evacuation of SICH was first reported in 1985 by L.M. Auer. Since then many publications in the literature were dedicated to this safe, short and perspective operative method, which rate reached in the last years 99\% (Nagasaka et al, 2008). Authors like Nagasaka T, Tsugeno M, and Inao S. et al, 2008-2009 and Nishihara et al, 2007 suggest that the endoscopic method realized precise and better evacuation through multifunctional cannula and give early recovery in the postoperative period in SICH patients than craniotomy. Hematoma contributes to local mass effect, elevates the ICP, increases the biochemical toxicity that results in vasospasm, which intensifies the local brain edema. Therefore this minimally invasive method applied early can reduce the secondary injury of the brain and can also contribute to avoid the consequences of early vasospasm associated with severe brain swelling and drastic elevation of the intracranial pressure (40). According to many authors another important finding is that early surgery utilizing the endoscope-assisted method has relatively low re-bleeding rate. Theoretically, this should lead to improved functional outcomes and decreased mortality rates. But according to the AHA/ASA Guidelines for the Management of Spontaneous Intracerebral Hemorrhage $(14,19)$, no clear evidence at present indicates that ultraearly removal of SICH improves functional outcomes or mortality rates. In addition, the authors mentioned that very early craniotomy may be harmful due to increased risk of recurrent bleeding. This recommendation was based on a trial of 11 patients randomized within 4 hours of hemorrhage onset, where rebleeding occurred in $40 \%$ of the patients treated within 4 hours compared to $12 \%$ of the patients treated within 12 hours using the craniotomy method $(21,22)$. On review of the literature, authors like Cho et al, 2006 and Nagasaka et al, 2009 suggest that endoscopeassisted ICH evacuation performed in the early stage is associated with a minimal rebleeding rate $(0 \%-3.3 \%)$ compared to the traditional craniotomy method $(5 \%-10 \%)$. Other advantages of the endoscope-assisted method include low complication rate, less operative time, less blood loss, improved evacuation rate, and early recovery of the patients. The results of our study confirm these potential benefits compared to the presented data in the literature $(40,42)$. Endoscope-assisted ICH evacuation may provide also a better hematoma evacuation rate with minimal damage to normal brain tissue. Due to the improvement of neuroendoscopic systems and instruments, recent studies have shown high rates of hematoma evacuation that ranged from $83.4 \%$ to $99 \%(10,16,23-28)$. As regarding the choice of the surgical procedure we 
prefer to use the temporal approach in all cases with deep situated hematoma localizations. The surgical concept of hematoma evacuation from in to out is a great advantage, shared by many authors in the literature. This is the shorter working distance, which increases the comfort of the procedure and make it most quickly, atraumatically, easy and safely. It avoids the so called early collapsing of the residual hematoma cavity and subsequent damage to the brain tissue. It is not difficult to evacuate the hematoma through the shortest distance from the cortical surface to its outer border. This is of importance not only for hematomas with volume of $50 \mathrm{ml}$, but also for larger than (16). Some authors advise that a posterior approach is better than an anterior approach for evacuating a thalamic hematoma because it avoids injury of the intracerebral veins $(5,22)$. The approach chosen depends of the extension of hematoma borders. As mentioned, our goal for these patients is to decrease the elevated ICP and remove the ICH and/or IVH if possible with minimal brain damage. As shown, better results were obtained in the younger group, than patients with advanced age. Great expectations of poor results were available in patients with advanced age, availability of seriously comorbidity, deep location of hematoma, volume of more than $70 \mathrm{ml}$ and GCS by admission of less than 8 points. Unlike the other authors we include patients with GCS score under 8 points. That explains to some extent our unsatisfactory results in the postoperative period - 10 severely disabled, 4 in vegetative state and 13 dead. Within the 12-24 hours period performed surgery gives better results due to the higher evacuation rate of the hematoma due to the usually easy suction of the clots. This opinion is in contradiction with the common belief that delayed hematoma suction is easy because of partial or total clots liquification. Evacuation of the deep situated basal ganglia hematomas and especially in the thalamus arouse skeptical atmosphere in some authors because of difficult running after surgery period and great percentage of severe disability $-86 \%(9,10,16$, $39,42)$. Those facts correlated with our results - from 12 operated patients with basal ganglia hematomas $10(83,3 \%)$ remain severely disabled and $4(7,1 \%)$ stay in vegetative state which means $25 \%$ of all 56 operated patients in our series. Our mortality rate was $23,2 \%$ - from 13 died 2 were with SDH, 4 with lobar, 4 with basal ganglia and
3 with intracerebellar hematoma. These results are due to the constellation of unfavourable factors - age, volume and localization of hematoma, neurological deficits so that to the most common cause of postoperative worsening - brain ischemia. Other serious factors like comorbidity play considerable part in the condition of the patients after the surgery and change-their prognosis. In all 56 patients $54(96,4 \%)$ were with concomitant deseases. There is no convincing evidence of benefit from any conservative medical treatment. But the role of surgery remains also controversial. Several prospective, randomized, controlled clinical trials have been undertaken to compare surgical and conservative treatment of $\mathrm{ICH}$, but they have been in a single center and small $(8,9,26-28$, $41,42)$. The prospective and randomized International Surgical Trial in Intracerebral Hemorrhage (STICH) is a controlled trial to determine whether the method of early neuroendoscopically assisted surgical evacuation of the hematoma will improve outcome compared to the tactics of initial medical treatment. Patients admitted with a SICH are suitable for the trial if they fulfill the inclusion and exclusion criteria for early surgical intervention. All the same, many of the authors suggest that the early and completely evacuation of SICH via this minimally invasive method may lead to improved outcome in these patients $(1,3,4,9,10,15,17$, $32,39-42)$.

\section{Conclusion}

The results in our series of 56 patients indicate that completely and early neuroendoscopically-assisted evacuation of SICH realized in the first $12-24$ hours after the hemorrhagic onset may gives chance to recovery of general condition and neurological features of the patients because it reduces the secondary injury of the brain and can also contribute to avoid the consequences of early vasospasm leading to brain swelling and elevation of the intracranial pressure. The re-bleeding, postoperative complications and mortality rates are low compared to the rates reported in the literature for patients who have undergone the traditional craniotomy method. This operative method as a minimally invasive procedure is safe, short and very effective in selected patients indicated to early surgical intervention. For all that, our study at this stage is of a preliminary character and involves another profound and prospective analysis in the next years. 


\section{References:}

1. Adeoye O, Broderick JP: Advances in the management of Intracerebral hemorrhage. Nat Rev Neurol 2010, 6: 593-601.

2. Adeoye O, Ringer A, Hornung R, Khatri P, Zuccarello M, Kleindorfer D.: Trends in surgical management and mortality of intracerebral hemorrhage in the United States before and after the STICH trial. Neurocrit Care 2010, 13: 82-86.

3. van Asch CJ, Luitse MJ, Rinkel GJ, van der Tweel I, Algra A, Klijn CJ: Incidence, case fatality, and functional outcome of intracerebral haemorrhage over time, according to age, sex, and ethnic origin: a systematic review and meta-analysis. Lancet Neurol 2010, 9(2): 167-176.

4. Balaji SP, Varma RG, Parthiban JKBC, Krishna KN, Varma RM, Srinivasa R, Acharya PT, Mruthyunjayana BP, Eesha M: Keyhole craniectomy in the surgical management of spontaneous intracerebral hematoma. Neurology Asia 2007, 12: $21-27$.

5. Auer LM.: Endoscopic evacuation of intracerebral haemorrhage. High-tech-surgical treatment - a new approach to the problem? Acta Neurochir (Wien) 1985, 74: 124-128.

6. Blacker DJ, Musuka T : Management of intracerebral hemorrhage in 2020. Future Neurol 2011, 6(6): 745-756.

7. Broderick JP, Connolly S, Feldman E, Hanley D, Kase C, Krieger D, Mayberg M, Moergenstern L, Odilvy CS, Vespa P, Zuccarello M: Guidelines for the management of spontaneous intracerebral hemorrhage in adults 2007 update. Stroke 2007, 38: 2001-2023.

8. Chen CC, Cho DY, Chang CS, Chen JT, Lee WY, Lee HC: Astainless steel sheath for endoscopic surgery and its application in surgical evacuation of putaminal haemorrhage. J ClinNeurosci , 2005, 12:937-940.

9. Chen CC, Lin HL, Cho DY: Endoscopic surgery for thalamic hemorrhage: a technical note. Surg Neurol 2007, 68:438-442.

10. Cho DY, Chen CC, Chang CS, Lee WY, Tso M: Endoscopic surgery for spontaneous basal ganglia hemorrhage: comparing endoscopic surgery, stereotactic aspiration, and craniotomy in noncomatose patients. Surg Neurol 2006, 65:547-556.

11. Elliott J, Smith M.: The acute management of intracerebral hemorrhage: a clinical review.Anesth Analg 2010, 110: $1419-1427$.

12. Flower O, Smith M : The acute management of intracerebral hemorrhage. Current Opinion Critical Care 2011, 17: 106-114.

13. Gang RK: Nontraumatic intracerebal hemorrhage. Medmerits 2011.

14. Gregson BA, Mendelow AD: International variations in surgical practice for spontaneous intracerebral hemorrhage. AHA/ASA Stroke 2003, 34: $2593-2598$.

15. Hossain M, Ahmed SU, Ansary SAA, et al: Surgical outcome of spontaneous intracerebral haematoma through keyhole craniectomy. Faridpur Med Coll J 2010, 5(2):60-62.

16. Hsieh PC, Cho DY, Lee WY, Chen JT: Endoscopic evacuationof putaminal hemorrhage: how to improve the efficiency ofhematoma evacuation. Surg Neurol, 2005, 64:147-153.

17. Kuo LT, Chen CM, Li CH, Tsai JC, Chiu HC, Liu LC, Tu YK, Huang AP : Early endoscope-assisted hematoma evacuation in patients with supratentorial intracerebral hemorrhage: case selection, surgical technique, and long-term results. Neurosurg Focus 2011 30 (4): E9.

18. Liebeskind DS : Intracranial Hemorrhage. Medscape Reference 2011, WebMD 1-10.

19. Mendelow AD, Gregson BA, Fernandes HM, Murray GD, Teasdale GM, Hope DT, et al: Early surgery versus initial conservative treatment in patients with spontaneous supratentorial intracerebral haematomas in the International Surgical Trial in Intracerebral Haemorrhage (STICH): a randomised trial. Lancet 2005, 365:387-397.

20. Mobbs R, Khong P: Endoscopic-assisted evacuation of subdural collections. J Clin Neurosci 2009, 16: 701-704.

21. Morgenstern LB, Demchuk AM, Kim DH, et al.: Rebleeding leads to poor outcome in ultra-early craniotomy for intracerebral hemorrhage. Neurology 2001, 56: 1294-1299.

22. Morgenstern LB, Hemphill JC III, Anderson C, et al.: Guidelines for the management of spontaneous intracerebral hemorrhage: a guideline for healthcare professionals from the American Heart Association/American Stroke Association. Stroke 2010, 41: 2108-2129.

23. Nagasaka T, Inao S, Ikeda H, Tsugeno M, Okamoto T: Inflation-deflation method for endoscopic evacuation of intracerebral haematoma. ActaNeurochir (Wien) 2008, 150:685-690.

24. Nagasaka T, Tsugeno M, Ikeda H, Okamoto T, Takagawa Y, Inao S, Wakabayashi T: Balanced irrigation-suction technique with a multifunctional suction cannula and its application for intraoperative hemorrhage in endoscopic evacuation of intracerebral hematomas: Technical note. Neurosurgery 2009, 65: 826-827.

25. Nagasaka T, Tsugeno M, Ikeda H, Okamoto T, Inao S, Wakabayashi T: Early recovery and better evacuation rate in neuroendoscopic surgery for spontaneous intracerebral hemorrhage using a multifunctional cannula:Preliminary study in comparison with craniotomy. J Stroke Cerebrovasc Dis 2009, 20: 208-213.

26. Nakano T, Ohkuma H, Ebina K, Suzuki S: Neuroendoscopic surgery for intracerebral haemorrhage — comparison with traditional therapies. Minim Invasive Neurosurg 2003, 46:278-283.

27. Nishihara T, Nagata K, Tanaka S, Suzuki Y, Izumi M, Mochizuki Y, et al: Newly developed endoscopic instruments for the removal of intracerebral hematoma. Neurocrit Car 2005, 2:67-74.

28. Nishihara T, Morita A, Teraoka A, Kirino TK.: Endoscopy-guided removal of spontaneous intracerebral hemorrhage: comparison with computer tomography-guided stereotactic evacuation. Childs Nerv Syst 2007, 23: 677-683.

29. Qureshi AI, Mendelow AD, Hanley DF: Intracerebral hemorrhage. Lancet 2009, 9(373): 1632-1644.

30. Reichart R, Frank S: Intracerebral hemorrhage, Indication for Surgical Treatment and Surgical Techniques. Open Critical Care Med J , 2011, 4: $68-71$.

31. Sahni R, Weinberger J: Management of intracerebral hemorrhage. Vasc Health Risk Management 2007, 3(5): 701-709.

32. Steiner T, Boesel J: Options to restrict hematoma expansion after spontaneous intracerebral hemorrhage. Stroke 2010, 41: 402-409.

33. Sudlow CL, Warlow CP: Comparable studies of the incidence of stroke and its pathological types : results from an international collaboration - International Stroke Incidence Collaboration. Stroke 1997, 28: 491-499.

34. Sung SK, Kim SH, Son DW, Lee SW: Acute spontaneous subdural hematoma of arterial origin. J Korean Neurosurg Soc 2012, 51: 91-93.

35. Teernstra OPM, Evers SMAA, Lodder J, Leffers P, Franke CL, Blaauw G: Stereotactic treatment of intracerebral hematoma by means of a plasminogen activator. A multicenter randomized controlled trial (SICHPA). Stroke 2003, 34(4): 968-974.

36. Thrift AG, Dewey HM, McDonnel RA, McNeil JJ, Donnan GA: Incidence of the major stroke subtypes: initial findings from the North East Melbourne Stroke Incidence Study (NEMESIS). Stroke 2001, 32: 1732-1738. 
37. Wang HS, Kim SW, Kim SH: Spontaneous chronic subdural hematoma in an adolescent girl. J Korean Neurosrg Soc 2013, 53: 201-203.

38. Wang X, Liang H, Xu M, Shen G, Xu L: Comparison between transsylvian-transinsular and transcortical-transtemporal approach for evacuation of intracerebral hematoma. Acta Chirurg Brazileira 2013, 28(2): 112-118.

39. Zheng JS, Yang F, Xu QS, Yu JB, Tang LL :Treatment of hypertensive intracerebral hemorrhage through keyhole transsylvian approach. J Craniofac Surg 2010, 21: 1210-1212.

40. Zhu H, Wang Z, Shi W: Keyhole endoscopic hematoma evacuation in patients. Turk Neurosurg 2012, 22(3): 294-299.

41. Zucacrello M, Andaluz N, Wagner KR : Minimally invasive therapy for intracerebral hematomas. Neurosurg Clin N Am 2002, 13(3): 349354.

42. Zuo Y, Cheng G, Gao DK, Zhang X, Zhen HN, Zhang W, et al:Gross-total hematoma removal of hypertensive basal ganglia hemorrhages: a long-term follow-up. J Neurol Sci 2009, 287:100-104.

Address:

Tony Avramov MD, PhD

Dept. Neurosurgery, St. Marina University Hospital,

Varna, BG,

tel. 0035952978813 ,

e-mail: toniavram@abv.bg 